\title{
Dermatology Medications Therapeutic Interchanges: A Narrative Reviews
}

Yousef Ahmed Alomi*, BSc. Pharm, MSc. Clin Pharm, BCPS, BCNSP, DiBA, CDE, Critical Care Clinical Pharmacists, TPN Clinical Pharmacist, Freelancer Business Planner, Content Editor and Data Analyst, Riyadh, Saudi Arabia. Faiz Abdullah. Bahadig, R.Ph, Informatics Pharmacist, Pharmaceutical Care Department King Abdul-Aziz Medical, City-WR-Jeddah, Ministry of National Guard, Saudi Arabia.

\section{Correspondence:}

Dr. Yousef Ahmed Alomi, BSc. Pharm, MSc. Clin Pharm, BCPS, BCNSP, DiBA, CDE, Critical care clinical pharmacists, TPN clinical pharmacist, Freelancer Business Planner, Content Editor and Data Analyst. P.O.BOX 100 Riyadh 11392, Riyadh, Saudi Arabia.

Phone no: +966504417712

E-mail:yalomi@gmail.com
Received: 15-7-2019;

Accepted: 20-10-2019

Copyright: (c) the author(s), publisher and licensee International Journal of Pharmacology and Clinical Sciences. This is an open-access article distributed under the terms of the Creative Commons Attribution Non-Commercial License, which permits unrestricted non-commercial use, distribution, and reproduction in any medium, provided the original work is properly cited.

This is an open access article distributed under the terms of the Creative Commons Attribution-NonCommercial-ShareAlike 4.0 License

Access this article online

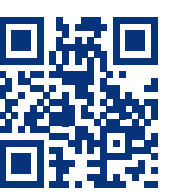

www.ijpcs.net

DOI:

10.5530/ijpcs.2020.9.25

\begin{abstract}
Objective: To review the dermatology medications therapeutic interchanges therapy. Methods: It is an extensive search, or fifty databases comprised the following through the Saudi Digital Library (SDL) searching engine. It included the various types of studies (meta-analysis, randomized controlled studies and observational studies) in the English language with human study only for the update May 2017. The search in terms of therapeutic interchange, medication, therapy and type of disease or medication base on therapeutics class of anti-psychiatric. The medication list and switch from one drug to substitute based on the literature found the search that has included comparative safety, efficacy and cost of the type of medication for each disease and national or international evidence-based guidelines. Results: The total number of studies after an extensive search with a specific term search was 487 studies. Of those, there were 107 duplicated studies, and 380 studies included for future assessment. After assessment, 375 Records were excluded due to Non dermatology therapeutics interchange. Of the previous search, there were 5 studies that had been found discussed the dermatology medications therapeutic interchanges. Conclusion: There were few studies about medications used in skin disorder therapeutic interchange. It is better to start for generic substitutes and based on the international Therapeutic dermatology guidelines. Key words: Dermatology Medications, Therapeutic interchange, Initiative, System, Saudi Arabia.
\end{abstract}

\section{INTRODUCTION}

The basic standards of healthcare institutions were medication hospital formulary that contained of medications list available $24 / 7$ day inside the institutions and suitable for the patients. Various methods to keep the medications all the time obtainable inside healthcare institutions and one of the popular ways were therapeutic interchange system. ${ }^{1}$ The system measured if the healthcare any medications not available for any reason, there is another medicines that replace it automatically. The system can be executed for all types of medications, including dermatology medications. The dermatology diseases need various duration of therapy from a few days to several months. The patients should obey to drugs until the disease recover. As a result, the concern medications or interchange should be available to target this goal. Few studies conducted on dermatology therapeutic interchange..$^{2-6}$ The majority of studies were the medications therapeutic interchange prevalence and used as alternative medications drove of therapeutic guidelines published in the litterateur as comparative medications and replace the drug of choice or second-line therapy. ${ }^{7-10}$ The authors not familiar with any investigations about dermatology medications therapeutic interchange discussed locally or Gulf and Middle East countries. The aim of the current review is to explore the dermatology therapeutic interchange medications based on scientific evidence or international guidelines and employed in the Kingdom of Saudi Arabia.

\section{MATERIALS AND METHODS}

It is extensive search or fifty databases included the following through Saudi Digital Library (SDL) searching engine; Willy online library, web of science, springer link, Taylor and Francis, Social Science Journal via ProQuest, Science Journal via ProQuest, Scopus, Scifinder, Science Direct, Sage Journal, Royal Society of Medicine, Royal Society of Chemistry, Psychology Journals via ProQuest. Pharmaceutical news index via ProQuest, Patient Education via MD consult, Drug via MD Consult, Oxford Journals via Oxford University, Ovid Journals, Nursing and Allied Health Sources via ProQuest, Nature Publisher group, Medline index via ProQuest, Medline complete via EBSCO, Medical Evidence Matter via ProQuest, IGI InfoSci Journals, Health Management via ProQuest, Health and Medical complete via ProQuest. Global Health DatabaseCABI, Family Health via ProQuest, Eric via ProQuest and EBSCO, Emerald, Dynamed via EBSCO, Directory of Open Access Journal (DOAJ), Current Content via Web of Knowledge, Dentistry and Oral Science via EBSCO, Clinical Key -Nursing, Clinical Key-Physician, CINAHL via EBSCO, Central via ProQuest, CBCA via ProQuest, Canadian Science Publishing. Cambridge Journals via Cambridge University, Britannica Academic, BMJ Journals, BMJ Clinical Evidence via BMJ Best Practice, BMJ Best Practice, Biology Journals via ProQuest, ACM Digital Library, Academic Search Ultimate 
via EBSCO, Cochrane Library Pubmed. In addition to Google, Scholar searched alone without SDL. It comprised the types of studies (meta-analysis, randomized controlled studies and observational studies) in the English language with human study only for the update May 2017. The search in terms of therapeutic interchange, medication, therapy and type of disease or medication based on therapeutics class. The medication list and switch from one drug to another based on the literature found the search that has included comparative safety, efficacy and cost of the type of medication for each disease and national or international evidence-based guidelines. ${ }^{7-10}$ The Dermatology medication interchange list included drug name, general dosing and frequency. All settings of patient care services inpatient or ambulatory care or community services oral medication encompassed. All dosage form medication will include in the list. All medications should include the Ministry of Health formulary. The location of studies included Saudi Arabia as top propriety if hasn't existed Gulf or Middle East counties included, if not found overall counties included. If not existed, the table recommended from the author's experiences.

\section{RESULTS}

The total number of studies after an extensive search with a specific term search was 487 studies. Of those, there were 107 duplicated studies, and 380 studies included for future assessment. After assessment, 375 Records were excluded due to Non dermatology therapeutics interchnage. Of the previous search, there were 5 studies that had been found discussed the dermatology medications therapeutic interchnages. Two of them were review articles, and 3 were the prevalence of cross-sectional studies related to types of medications used in the therapeutic interchange system. All of the studies were not included for assessment because there were not fitted with research criteria (figure 1).

\section{DISCUSSION}

Therapeutic interchange medication involved in several types of medications; for instance, cardiovascular medications, antibiotics, NSAIDs and gastric ulcer medications. ${ }^{2-6}$ However, the employment of therapeutic interchange within dermatology disease is rare and most of the literature not discussed them. As a result, based on the author's knowledge, there are no studies that had not been done about dermatology therapeutic. However, most of the therapeutic interchange can be used during the international therapeutic guidelines of dermatology disease management. $^{7-10}$ Each dermatology disease had several classes of management and each class had several medications. The disease had several equal options of management based on comparative efficacy and safety studies, but not therapeutic interchange studies. As a result, the authors and his colleagues recommended medications list of therapeutic interchange for dermatology medications (Table 1), that including the medications for infectious diseases of the skins orally or topically, topical steroid therapy, anti-allergies medications. All previous therapeutic interchange classes drove from international therapeutic guidelines. That keeps all the demand for medications for disease medications available all the time without missing any doses. Besides, using generic medications instead of the brand drug and using cheaper medications in each therapeutic lasses and subsequent saving significant cost for dermatology therapy then implement therapeutic interchange guidelines. ${ }^{6,11-14}$ The dermatology therapeutic interchange is serious through the implementation of Saudi managed care pharmacy and new Saudi vision 2030. ${ }^{15,16}$

\section{CONCLUSION}

Therapeutic interchange medications used for the dermatology section is not universal. There were few studies to authenticate it. Further studies demand to standardized medications therapeutic interchange used for skin diseases. However, therapeutic interchange in dermatology specialty is recommended to start accordingly to the international guidelines of skin disorders diseases.

\section{ACKNOWLEDGMENT}

None.

\section{CONFLICT OF INTEREST}

The authors declare that there is no conflict of interest.

\section{ABBREVIATIONS}

MOH: Ministry of Health; KSA: Kingdom of Saudi Arabia; USA: United States of America; TI: Therapeutic Interchange; USD: United States Dollar; SDL: Saudi Digital Library.
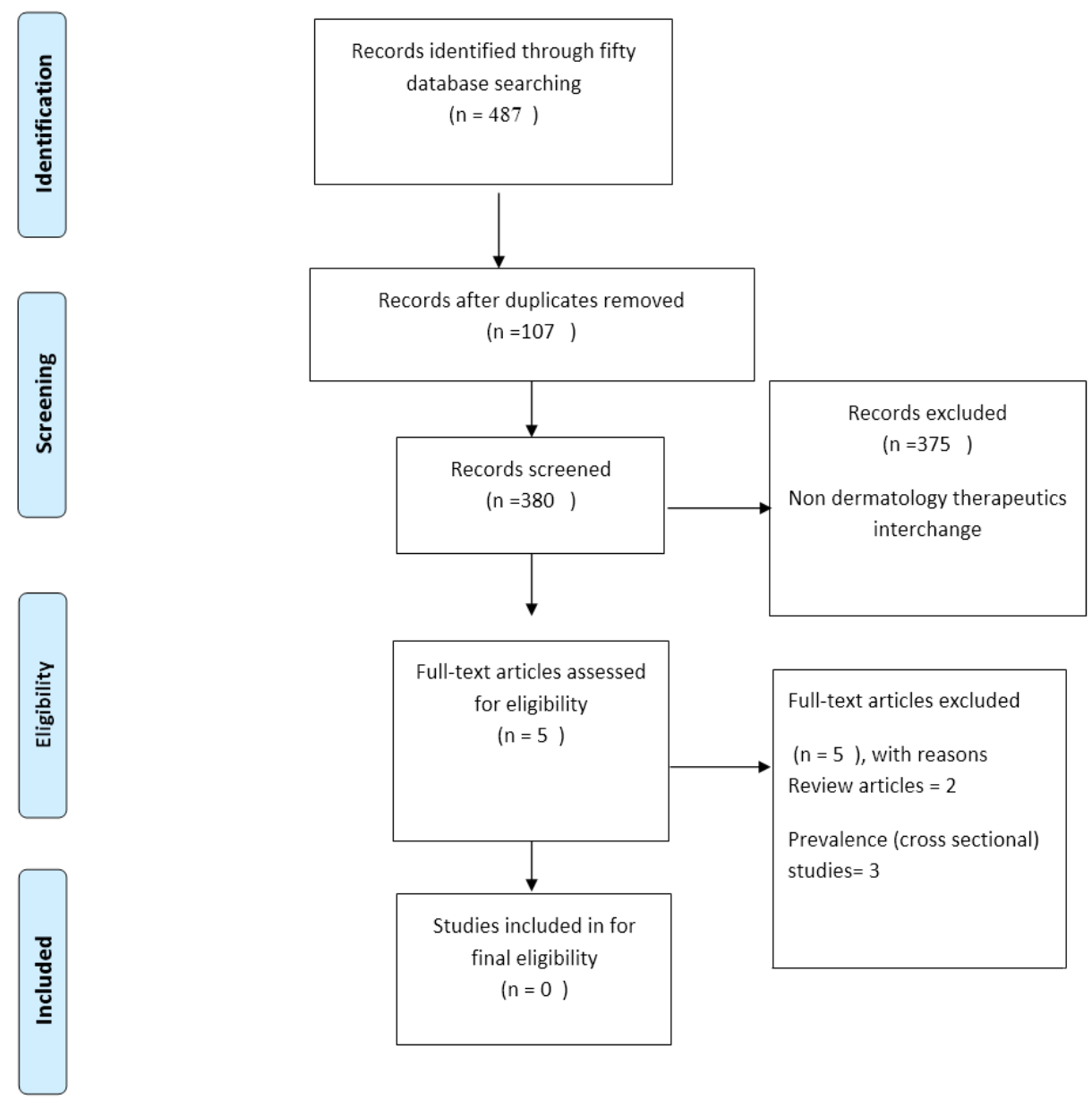

Figure 1: Results of searching the literature. 


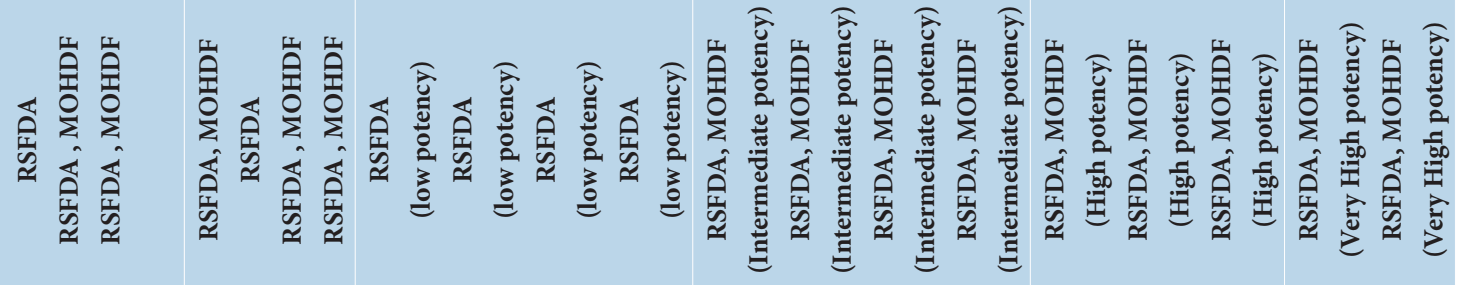

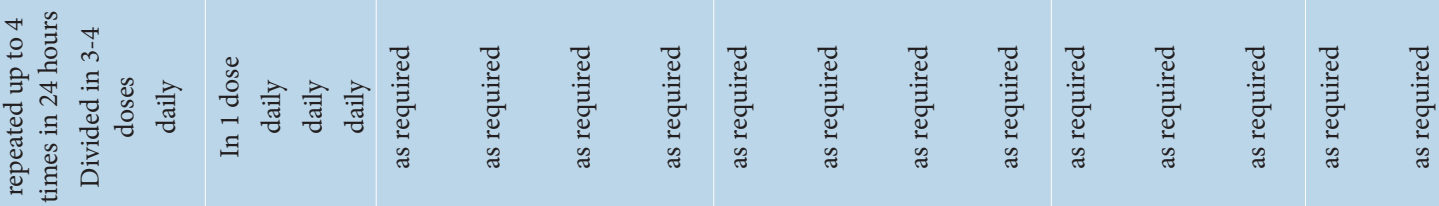

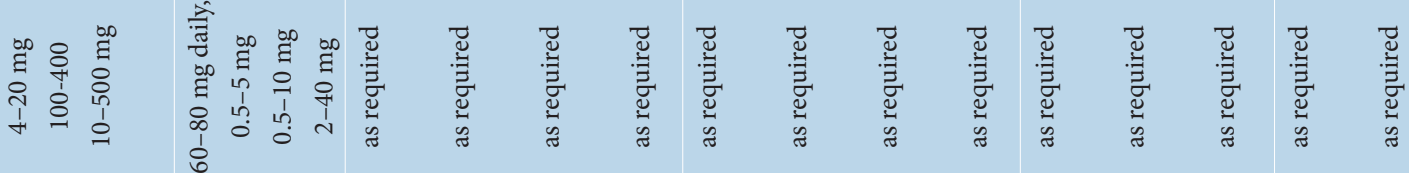

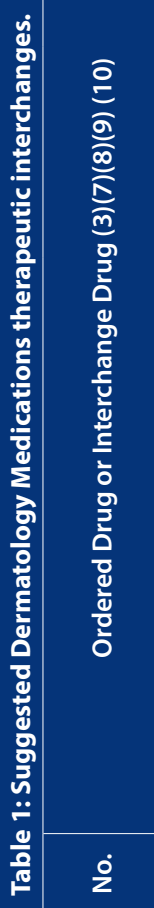

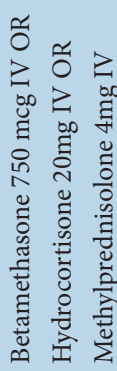
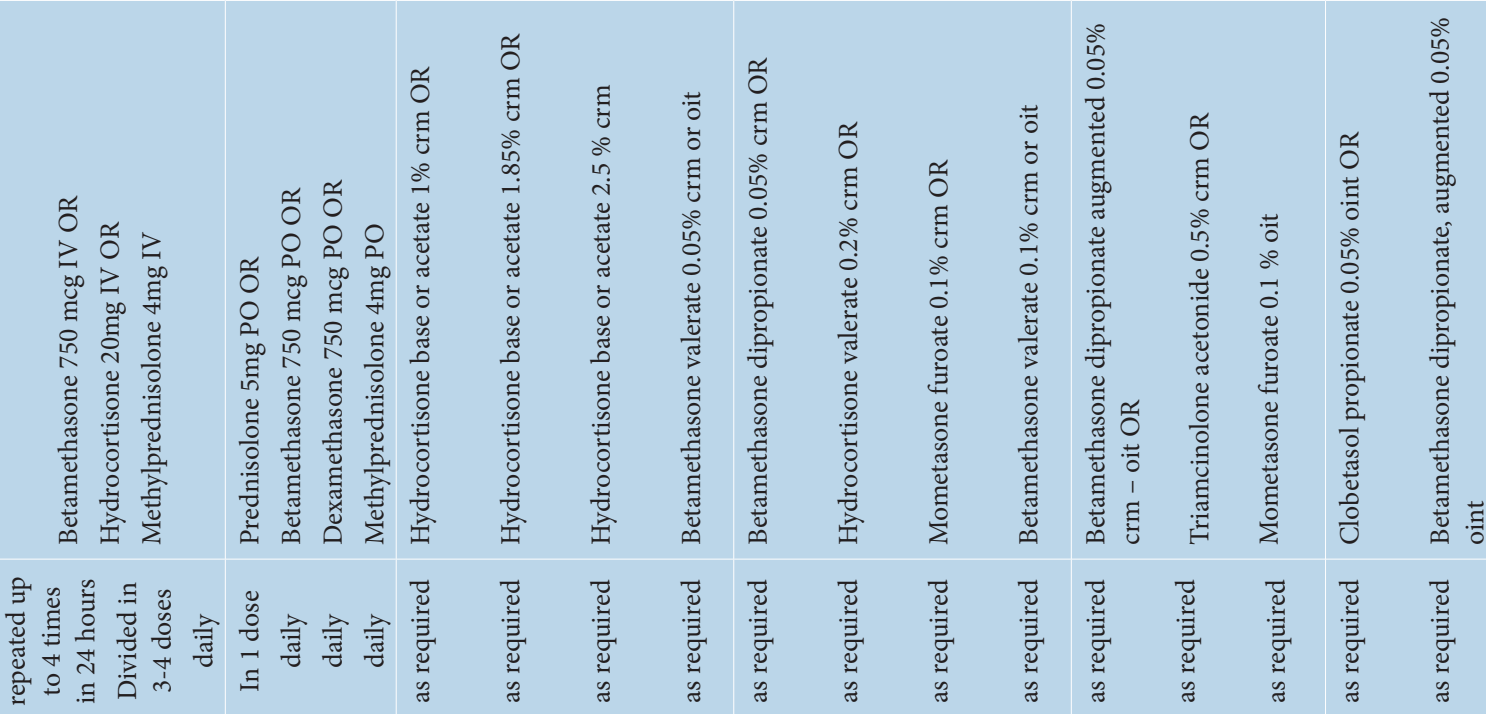

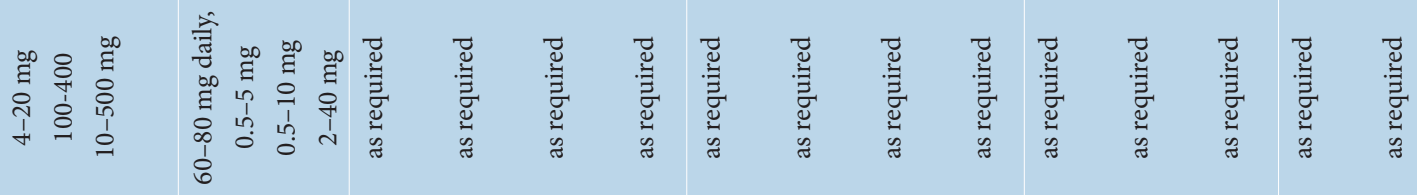
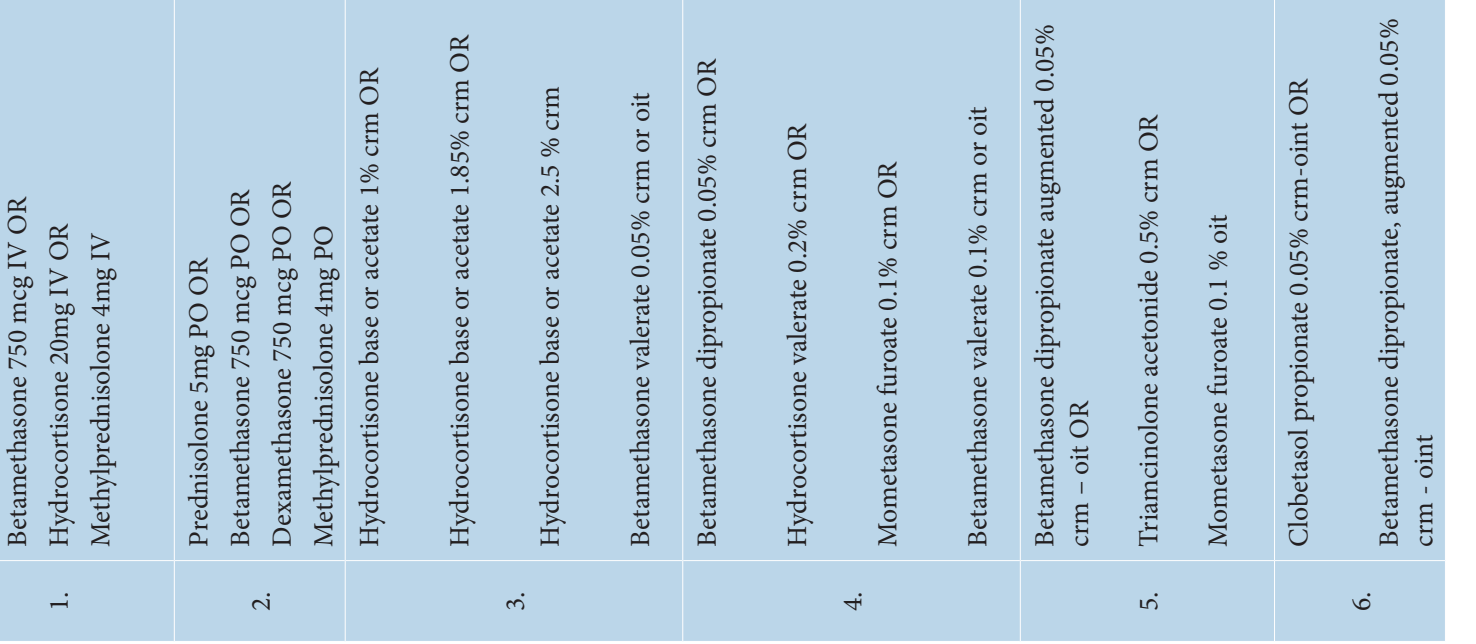


\section{ORCID ID}

Yousef Ahmed Alomi https://orcid.org/00000003-1381-628X

\section{REFERENCES}

1. Carroll NV. Formularies and therapeutic interchange: The health care setting makes a difference. Am J Heal Pharm. 1999;56(5):467-72.

2. Schachtner JM, Guharoy R, Medicis JJ, et al. Prevalence and cost savings of therapeutic interchange among U.S. hospitals. Am J Heal Pharm. 2002;59(6):529-33.

3. Oh T, Franko TG. Comprehensive therapeutic interchange program in a community hospital. Am J Hosp Pharm. 1991;48(7):1471-7.

4. Carroll NV. Therapeutic interchange in community pharmacies in Virginia. Am J Heal Pharm. 2000:57(9):882-6.
5. Eurich D, Poulin S, Semchuk W, et al. Therapeutic interchange in Canadian hospitals: A national survey. Can J Hosp Pharm. 2001;54(1):28-34.

6. Gray T, Bertch K, Galt K, et al. Guidelines for therapeutic interchange. Pharmacotherapy. 2005; 25(11):1666-80

7. Wells BG, DiPiro JT, Schwinghammer TL, et al. Pharmacotherapy Handbook. Ten Edition. 2017;1187.

8. Baxter K, Aikman K, Luckhurst R, et al. British National Formulary 78 (BNF). Royal Pharmaceutical Society. 2003;1-1701.

9. Ministry of Health. Ministry of Health Formulary. 2012.

10. Afifi T, Gannes GD, Huang $C$, et al. Topical therapies for psoriasis. Can Fam Physician. 2005;51(4):519-25

11. Mills EJ, Gardner D, Thorlund K, et al. A users guide to understanding therapeutic substitutions J Clin Epidemiol. 2014;67(3):305-13.

12. Wall DS, Abel SR. Therapeutic-interchange algorithm for multiple drug classes. Am J Heal
Pharm. 1996;53(11):1295-6.

13. Holmes DR, Becker JA, Granger CB, et al. ACCF/ AHA 2011 Health Policy Statement on Therapeutic Interchange and Substitution. Circulation. 2011 124(11):1290-310.

14. Compendium AMAP, Vol HP, Ama T. AMA policy on drug formularies and therapeutic interchange in inpatient and ambulatory patient care settings. Am J Hosp Pharm. 1994;51(14):1808-10.

15. AlomiYA, Alghamdi SJ, Alattyh RA. Saudi Managed Care Pharmacy (SMCP): New initiative system of $\mathrm{MOH}$ Prescriptions Dispensed Through Community Pharmacies. J Pharm Pract Community Med 2017:3(3):145-53.

16. Alomi YA. New Pharmacy Model for Vision 2030 in Saudi Arabia. J Pharm Pract Community Med. 2017;3(3):194-6.

17. Saudi Food and Drug Authority. List of human medicine and herbal health. 2019. Cited 2019 Jun 17. Available from: https://www.sfda.gov.sa/en/drug/ resources/Pages/DrugsUnderRegistrations.aspx. 